\title{
Erratum to: Dying with dignity according to Swedish medical students
}

\author{
Marit Karlsson • A. Milberg • P. Strang
}

Published online: 8 February 2011

(C) Springer-Verlag 2011

Erratum to: Support Care Center

DOI 10.1007/s00520-005-0893-5

The authors wish to clarify the complete affiliations of the first author. Marit Karlsson's affiliations are the Karolinska Institutet, Stockholm and the Unit of Advanced Palliative Home Care, LAH-kliniken, Universitetssjukhuset i Linköping, 58185 Linkoping.

The online version of the original article can be found at http://dx.doi. org/10.1007/s00520-005-0893-5.

M. Karlsson $(\bowtie)$

Karolinska Institutet, Stockholm and the Unit of Advanced

Palliative Home Care, LAH-kliniken,

Universitetssjukhuset i Linköping,

58185 Linkoping, Sweden

e-mail: marit.karlsson@ki.se

\section{A. Milberg}

Palliative Care Competence Centre, Department of Welfare and Care, Linköpings Universitet and LAH-kliniken,

Universitetssjukhuset i Linköping,

58185 Linkoping, Sweden

e-mail: anna.milberg@lio.se

\section{P. Strang}

Karolinska Institutet, Stockholm, Stockholms sjukhem,

Mariebergsgatan 22,

11235 Stockholm, Sweden

e-mail: peter.strang@ki.se 